\title{
Automated monitoring of bee behaviour using connected hives: Towards a computational apidology
}

\author{
Paul Marchal, Alexis Buatois, Stéphane Kraus, Simon Klein, \\ Tamara GoMez-Moracho, Mathieu LiHOREAU \\ Research Center on Animal Cognition (CRCA), Center for Integrative Biology (CBI); CNRS, University Paul Sabatier, \\ Toulouse, France
}

Received 11 March 2019 - Revised 13 September 2019 - Accepted 7 November 2019

\begin{abstract}
A major difficulty in studying the behaviour of social insects, such as bees, is to collect quantitative data on large numbers of individuals and over long periods of time, in sometimes dark and not easily accessible nests. Over the past decade, connected hives equipped with large sets of sensors to monitor real-time data about bee colony health and environmental conditions have been increasingly used in fundamental research, precision beekeeping and outreach programs. Here, we argue that combining these connected hive systems with automated movement tracking devices to obtain long-term data about the behaviour of bees inside and outside the hive can lead to major breakthroughs by helping discover new behaviours and compare data across labs and species. First, we describe the main sensors and hive parameters commonly used in connected hives used for honey bee and bumblebee colonies. Next, we discuss how developing more integrated systems connecting bees, hives and their environment, will help ask novel fundamental questions on bee behaviour and ecology.
\end{abstract}

\section{connected hive / honey bee / bumblebee / automated monitoring / quantitative ethology / sensors}

\section{INTRODUCTION}

Despite thousands of years of domestication and more than a century of academic research on bee behaviour, many aspects of the behavioural biology and ecology of bees remain poorly understood (Goulson 2010; Seeley 2010). This gap of knowledge is due to major technical difficulties for collecting quantitative data about the everyday activities of such small and fast-moving insects. Identifying individual bees among several thousands, observing their interactions in dark and busy nests, and monitoring their flights across

Corresponding author: M. Lihoreau, mathieu.lihoreau@univ-tlse3.fr

Paul Marchal and Alexis Buatois contributed equally to the work

Handling Editor: David Tarpy large spatial scales are among the multiple challenges that have limited these investigations so far.

To address this problem, researchers have developed experimental hives and equipped bees with various kinds of tags that facilitate behavioural observations. Some of the most important breakthroughs have been made using flat glass hives. Famously, by observing inside hives, Darwin and Teigmeier broke the mystery of the perfect architecture of honey bee combs, showing that hexagonal cell-building is an emergent process reminiscent of round cell-building exhibited by less social bee species (Darwin 1859). A century later, von Frisch decoded the behavioural sequence honey bee foragers display on the combs to convey locational information about food resources, a unique abstract communication in insects known as the 'waggle dance' (von Frisch 1967). More recently, researchers have introduced electronic sensors into bee hives (e.g. (Struye et al. 1994; Woods 1957)) 
to automatically monitor physicochemical and/or biological parameters associated to colony health status (for reviews, see Bromenshenk et al. 2015; Meikle and Holst 2015). The first standalone 'connected' honey bee hives, combining scales under the hive to measure honey production, bee-counters at the hive entrance to monitor foraging activity, temperature and relative humidity sensors inside the hive to assess the ability of colonies to maintain homeostasis, and weather stations to keep track of local environmental conditions, were developed in the 1990s (Bromenshenk et al. 1996). Modern connected hive systems now include acoustic and vibration sensors to measure communication (Bencsik et al. 2015; Vidrascu et al. 2016), infrared imaging for estimating the size of the colonies (Basile et al. 2008; Edwards Murphy et al. 2015; Shaw et al. 2011), gas concentration to assess the metabolic activity of bees (Ohashi et al. 2009; Seeley 1974), and cameras to monitor social interactions in the hive (Gernat et al. 2018; Wario et al. 2017).

With the raise of the Internet of Things (IoT), connected hives are rapidly developing and increasingly used outside academic research, for precision beekeeping, commercial pollination, but also as an education tool for outreach events and science dissemination (Debauche et al. 2018). In 2018, for instance, $13 \%$ of French beekeepers used commercial connected hives systems in their apiary (Lettmann and Chauzat 2018). When deployed in sufficient numbers, these sentinel hives provide precious information about the potential strength of all colonies in an apiary. The data are typically sent online on a dedicated website or smartphone application, enabling beekeepers to make fast and informed decisions for managing their stock and honey production.

While bee researchers are increasingly using sensors to monitor specific hive parameters, all available sensors have rarely been combined, for instance to explore potential relationships between the behaviour of individual bees, their past experience, the performance history of colonies, and the environmental conditions around the hive (weather, forage quality, beekeeping practices, use of agricultural chemicals), an approach that is not possible with conventional hives. Here, we argue that bee research can greatly benefit from a broader utilisation of connected hive technologies. High-throughput quantification of behaviour, sometimes called 'ethomics' (Branson et al. 2009), is an emerging approach in behavioural biology. Modern methods from computer science and engineering to automatically measure and analyse behaviour now offer the possibility for collecting larger datasets, discovering features that humans cannot, and providing a vocabulary for discussing and describing behaviour that is consistent across labs and species that one wants to compare (Brown and de Bivort 2018). While such studies have so far mostly been restrained to model animals in the lab (e.g. drosophila, mice (Egnor and Branson 2016)), connected bee hives provide a unique opportunity to start extending the approach out of the lab and study complex behaviours in their ecological context.

In this review article, we describe the main sensors and measures commonly used in connected hives and discuss how combining these approaches with automated movement tracking systems will help link investigations of bee behaviour inside and outside the hive. Our aim is not to provide a comprehensive review of all the sensors available (for such reviews, see Bromenshenk et al. 2015; Meikle and Holst 2015). Rather, we discuss how developing more integrated monitoring systems, with multiple sensors to connect information about bee behaviour, hive function and the external environment, will help explore new grounds in bee biology.

\section{WHAT IS MEASURED BY CONNECTED HIVES?}

Regardless of their usage (e.g. research, beekeeping, outreach), the main objective of connected hives is to inform in real time about the state of a bee colony and the quality of its environment. It is therefore important that the systems measure a set of insightful parameters whose variations can be interpreted independently from each other or in combination. Here, we describe some of these parameters and the main technologies used to monitor them (see summary in Table I).

\subsection{Temperature and humidity}

Connected hives are typically equipped with temperature and humidity sensors. Variations in 
Table I. Main technologies used in connected hives and where to find them. For extensive reviews of sensors, see Bromenshenk et al. (2015) and Meikle and Holst (2015)

\begin{tabular}{|c|c|c|c|}
\hline & Observations & Tools & References \\
\hline \multirow[t]{6}{*}{ Inside the hive } & Temperature & Temperature sensor & Stalidzans et al. 2017; Zhu et al. 2019 \\
\hline & & Thermal camera & $\begin{array}{l}\text { Basile et al. 2008; Edwards-Murphy } \\
\text { et al. 2015; Shaw et al. } 2011\end{array}$ \\
\hline & Humidity & Humidity sensor & Stalidzans et al. 2017 \\
\hline & Sound & Microphone & Bencsik et al. 2015; Vidrascu et al. 2016 \\
\hline & Weight & Weighing scale & Stalidzans et al. 2017 \\
\hline & Bee dance & Camera $+2 \mathrm{D}$ bar coded tags & Wario et al. 2017; Wild et al. 2018 \\
\hline \multirow[t]{5}{*}{$\begin{array}{l}\text { Climate and } \\
\text { stressors }\end{array}$} & $\begin{array}{l}\text { Temperature } \\
\text { Humidity }\end{array}$ & $\begin{array}{l}\text { Weather station or satellite } \\
\text { observation }\end{array}$ & Mendelsohn et al. 2007 \\
\hline & Wind & & \\
\hline & Rain & & \\
\hline & Light & Light sensor & $\begin{array}{l}\text { Bai and } \mathrm{Ku} 2008 \text {; Burrill and } \\
\text { Dietz } 1981\end{array}$ \\
\hline & Pollutant & Pollutant sensor & Choi et al. 2009 \\
\hline \multirow{3}{*}{$\begin{array}{l}\text { Foraging } \\
\text { behaviour traffic }\end{array}$} & Bee traffic & Counting system & Alaux et al. 2014, Crall et al. 2018a \\
\hline & Space use & Radar tracking & Lihoreau et al. 2012 \\
\hline & Flower visitation & $\begin{array}{l}\text { Artificial flowers combined } \\
\text { with camera or RFID reader }\end{array}$ & Lihoreau et al. 2012; Ohashi et al. 2008 \\
\hline
\end{tabular}

these two parameters can inform about changes in colony sizes. Honey bees are ectothermic insects that collectively regulate in-hive temperature (Simpson 1961) and humidity (Ayton et al. 2016; Human et al. 2006) in order to maintain optimal colony function, such as queen egg production and brood development. Any failure in doing so, as identified by in-hive sensors, may indicate an abnormal drop in population size in weak colonies (Stalidzans et al. 2017). However, when measured to specific areas in the hive (e.g. bottom part of the first frame), an increase of temperature can also predict imminent swarming (i.e. when the old queen and about a third of the workers leave the hive to found a new colony) (Zhu et al. 2019).

\subsection{Weight}

Connected hives also typically include weight scales under the nest comportment (Holst and Meikle 2018; Meikle et al. 2018). On the short term, variation in colony weight can inform about the overall traffic of bees entering and departing the hive, a proxy for foraging activity (Meikle et al. 2008), or swarming. On the longer term, however, gradual colony weight variations can be related to changes in nectar and pollen availability, honey production and brood development (Flores et al. 2019).

\subsection{Weather}

Colony foraging activity is correlated to external parameters such as light intensity, humidity, temperature, wind velocity and atmospheric pressure (Seeley 2014). All these parameters are now easily accessible using weather stations (Mendelsohn et al. 2007). With the increase of commercial pollination practices, maximising the activity of honey bee foragers over short periods of time has become a major challenge for beekeepers (Breeze et al. 2014). High-resolution weather data can therefore inform about pollination efficiency, allowing beekeepers to adjust the number and locations of hives needed at a given time. Good weather parameters, such as elevated light intensity, are usually correlated with a high 
level of bee activity (Bai and Ku 2008; Clarke and Robert 2018).

\subsection{Bee traffic}

The traffic of foragers at the hive entrance can be an indicator of foraging activity, food availability, food demand, colony age structure and colony growth. To measure the in and out movements of foragers, it is possible to mark individual bees with uniquely identified tags that are recognised by sensors at the hive entrance (e.g. radiofrequency identification (RFID) (de Souza et al. 2018; Streit et al. 2003) (Figure 1a), image recognition of coloured number tags (Alaux et al. 2014) (Figure $1 \mathrm{~b}$ ) or image recognition of 2D bar coded papers (Crall et al. 2018a) (Figure 1c)). For instance, long-term recordings of the traffic of bumblebee foragers revealed that individuals adjust their activity to daylight duration (Stelzer et al. 2010) and tend to perform more frequent and longer foraging bouts, but also to collect less food, after exposure to pesticides (Gill et al. 2012). At the individual level, these data also yielded information about the contribution of each bee to the colony workforce, showing that a small proportion of the foragers (i.e. 'elite' bees) is responsible for most of food collection (Klein et al. 2019; Tenczar et al. 2014).

\subsection{Nectar and pollen collection}

Efficient colony foraging relies on the coordinated activities of up to hundreds of workers
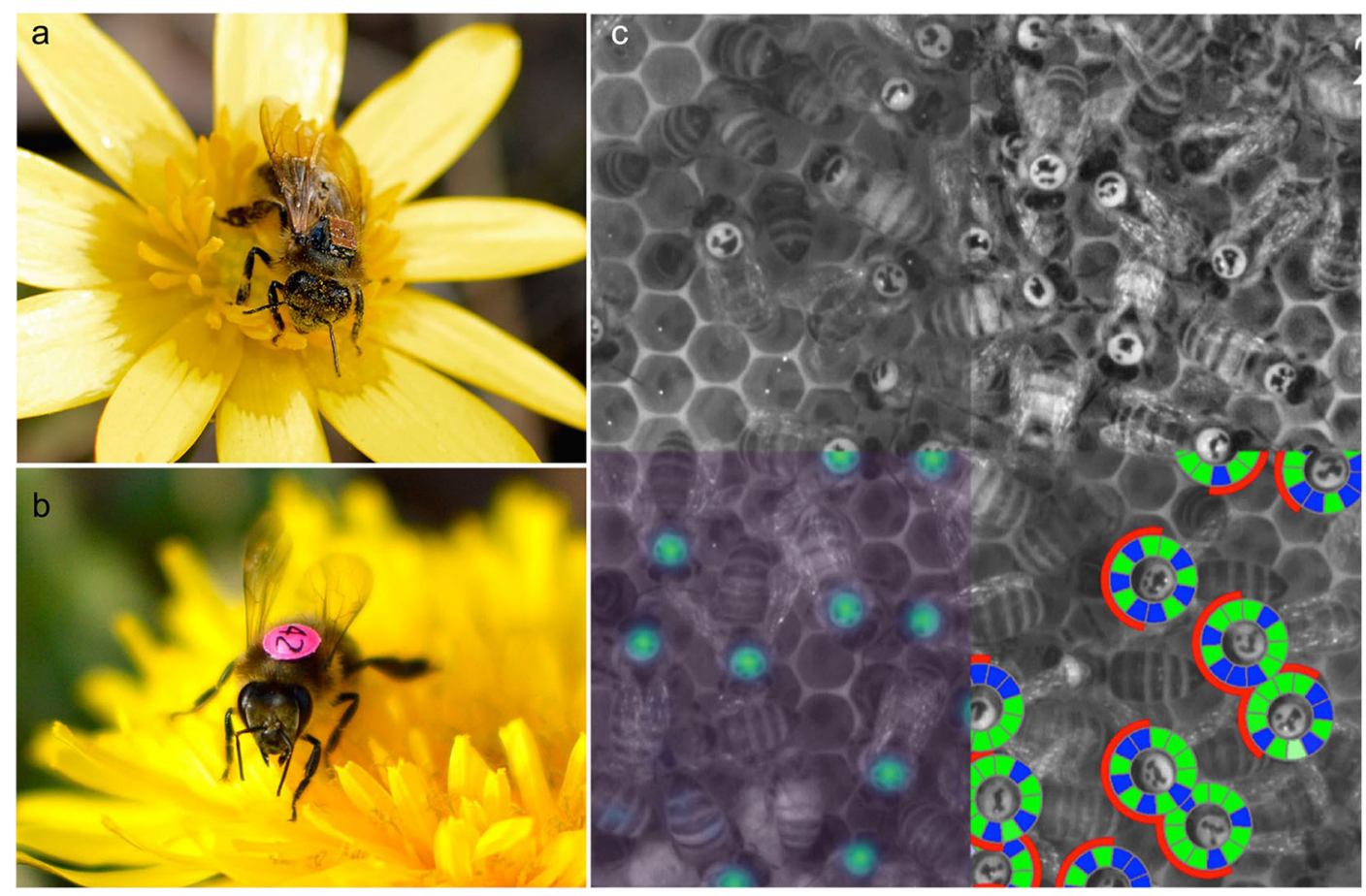

Figure 1. Recording bee behaviour in the hive and at the hive entrance. Bees can be marked with uniquely identified a radiofrequency identification (RFID) tags, $\mathbf{b}$ coloured number tags or $\mathbf{c} 2 \mathrm{D}$ bar coded paper tags on their thorax for individual recording of their social interactions (on the comb) and foraging activity (at the hive entrance). $\mathbf{c}$ In this example, behavioural tracking was used to analyse honey bee waggle dances. Top left: original image. Top right: pre-processed image. Bottom left: 'localiser' step for which the position of the tags is identified. Bottom right: 'decoder' step for which the 2D bar code is decoded thus providing the orientation of each individual bee. Red semicircle indicates the front of the bee, green and blue sections represent the binary code (12 bits) identifying the individual. Picture credits: a and b Tamara Gómez-Moracho, c Wild et al. (2018) 
to collect water, nectar (main source of carbohydrates) and pollen (main source of protein and fat) in amounts and balances that sustain colony growth and maintenance (Wright et al. 2018). Using motion detection cameras and RFID sensors at the hive entrance, it is possible to identify the type of food (nectar/water or pollen) collected by each forager and how this varies through time. This approach revealed a combined specialisation of bumblebee foragers for nectar and pollen (Russell et al. 2017) as well as the impact of different types of environmental stressors on pollen collection by honey bee foragers (Bordier et al. 2018).

\subsection{Social interactions}

A honey bee colony contains up to several thousands of workers that must exchange information quickly and reliably for efficient food recruitment. Foragers indicate the location of valuable food resources to their nestmates through the waggle dance (Figure 1c) (von Frisch 1967). Studying dances and the interactions between 'dancers' and 'followers' that take place all day long in the dark is experimentally challenging. Infrared video recordings combined with post-processing image algorithms now provide solutions to automatically detect and decode these interactions in real time (Wario et al. 2017; Wild et al. 2018), a promising approach to investigate how colonies dynamically exploit resources in complex natural environments. Beyond the waggle dance, extensive analyses of more the 1.2 millions of social interactions in honey bee hives using computer vision revealed that bees do not interact randomly but form social networks characterised by burst interactions that allow for fast spreading of information or food (Gernat et al. 2018).

\subsection{Temperature of individual bees}

Honey bee workers actively regulate the temperature of the comb on which the brood is located. Infrared imaging of in-hive conditions started to unravel the complex role of food exchange networks in brood comb homeostasis, demonstrating that heating bees that warm up the brood get their fuel (honey) delivered by cooler bees that shuttle between brood and store combs (Basile et al.
2008). Remote thermographic analyses of honey bee hives, using paint to identify individual bees with thermal cameras in glass hives, also revealed caste-dependent sleep patterns, in which older workers generally sleep closer to the perimeter of the nest in colder regions, while younger workers tend to sleep closer to the centre of the nest and spend more time asleep than awake when surrounded by uncapped brood (Klein et al. 2014).

\subsection{Vibration and sound}

Relatively little is known about the tactile and acoustic communication of bees because vibrational patterns in the hive are complex and diffuse (Sandeman et al. 1996 1996). Nonetheless, studies using accelerometers inside the wax of the hive frames have begun to explore these phenomena, showing that the amplitude of vibrational oscillations produced by honey bee workers is correlated with the brood cycle of the colony, so that high and low vibrational amplitudes indicate full and empty cells, respectively (Bencsik et al. 2015). Analyses of sound data also revealed a rich acoustic communication in the honey bee hive. Longterm microphone recordings of colonies showed the existence of bee-produced sounds ('piping') directed by workers towards dancing bees (Rangel and Seeley 2008). This behaviour is expressed in conditions of stress so that foragers that are attacked at a food source enter in contact with dancing bees that advertise the site and emit the piping danger signal that causes the dancer to stop dancing (Nieh 2010). Modifications of the sounds produced by in-hive honey bees have also been correlated with the presence and absence of a queen in the colony (Cejrowski et al. 2018).

\subsection{Crossing data from different measures}

Importantly, all these sensors yield complementary information and in many cases only their combined responses can reveal specific biological processes, necessary for a precise assessment of colony status. For example, while a long-term weight loss in a newly founded colony may be first interpreted as a reduction in queen brood production due to unfavourable foraging conditions, its combination with good weather 
parameters may rather indicate a reduction of colony foraging efficiency, for instance due to an exposure to pesticides or parasites that disorient foragers (Henry et al. 2012) and reduce their activity (Lach et al. 2015). If a gradual colony weight loss is associated with a unidirectional flow of foragers (i.e. foragers leave the hive but do not come back) this is likely linked to pathogens or parasites infections that induce colony avoidance behaviours to limit contagion (Higes et al. 2008).

\section{BEYOND CONNECTED HIVES: CONNECTING NESTS, BEES AND FLOWERS}

Recent experimental work has gone a step further by using automated movement tracking systems to monitor the foraging behaviour of honey bees and bumblebees, and combining these technologies with in-hive sensors in order to connect both the inside and the outside of the hives.

\subsection{In-nest behaviour and foraging activity}

Sensors have been combined to correlate the foraging activity of bees to their in-hive individual experience. Using 2D bar coded paper tags (Figure 1c), the spatial locations and body orientations of all bumblebees in a colony were tracked every $10 \mathrm{~min}$ for up to 2 weeks, and their foraging activity was recorded with a motion-activated camera at the nest entrance (Crall et al. 2018a). Artificial removal of foragers in the colony showed that in-nest spatial fidelity and frequent interactions with food storage pots (not nestmates or brood) enhanced the probability of hive workers to become foragers (Crall et al. 2018a). A similar approach was used to measure social interactions among bumblebees, showing that imidacloprid, a common neonicotinoid, affects nursing, social interactions, and nest construction behaviours by workers at sublethal doses (Crall et al. 2018b; Tsvetkov et al. 2017). Recent attempts have been developed to correlate local variations of environmental conditions to changes in behaviour and interactions in honey bee hives (Ngo et al. 2019), thus providing a quantitative tool allowing a real-time assessment of different settings within and outside the hive.

\subsection{Foraging activity and spatial behaviour}

Other studies combined sensors at the colony entrance and on artificial flowers to link the foraging activity of bees with their spatial movements. For instance, automated tracking of flower visits by bumblebees using RFIDs (Figure 1a) showed that foragers tend to develop routes minimising travel distance between multiple flowers (Ohashi et al. 2007), a behaviour also observed in honey bees (Buatois and Lihoreau 2016). This routing behaviour was later described at larger spatial scales, in the field, using motion sensitive cameras on flowers (Figure 2a) combined with harmonic radar (Figures $2 \mathrm{~b}$ and $\mathrm{c}$ ) to record the 2D flight paths of bumblebees during route formation and stabilisation (Lihoreau et al. 2012; Woodgate et al. 2017).

\subsection{Spatial behaviour and social interactions}

Automated recording of bee traffic at the nest entrance and bee visits to flowers also gave interesting insights into how multiple bees interact to exploit a common array of flowers. In experimental conditions when two bumblebees forage in the same set of artificial flowers, the most experienced foragers tend to develop a route and remain faithful to it (Ohashi et al. 2008), sometimes chasing away less experienced foragers from flowers (Lihoreau et al. 2016). Presumably, this interference behaviour encourages newly arrived foragers that have little experience of the environment to explore other options, ultimately favouring space partitioning among nestmates and efficient colony foraging (Pasquaretta et al. 2019).

\section{FUTURE DIRECTIONS}

Methods and technologies for continuous monitoring of bee hives have long been used in fundamental research to monitor selected parameters and address specific scientific questions (Bromenshenk et al. 1996). Since about 15 years, standalone connected hive systems, equipped 

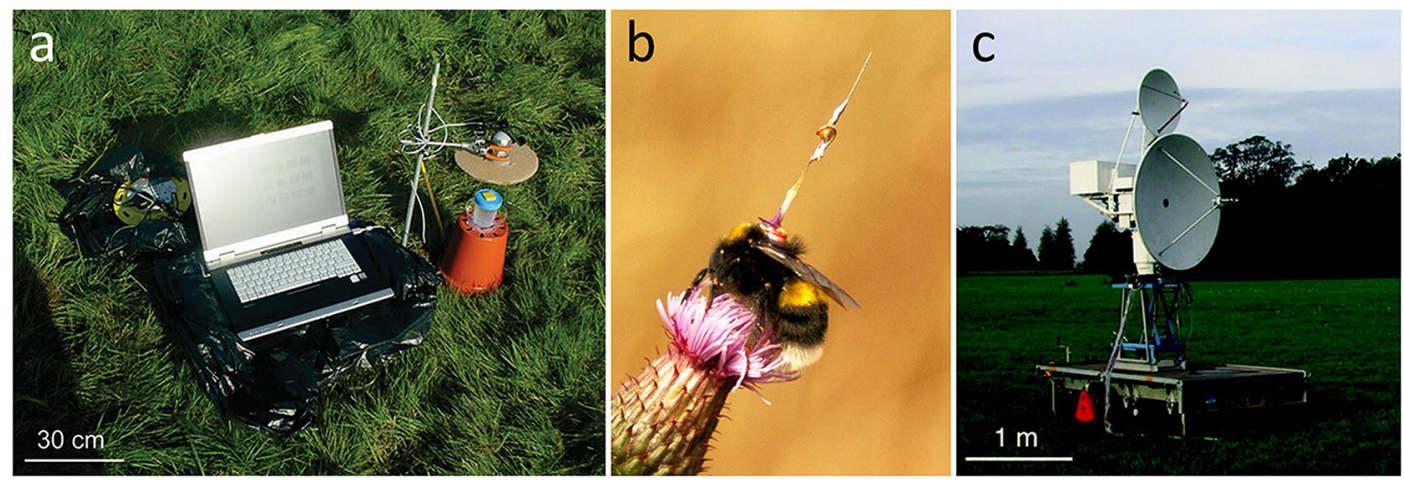

Figure 2. Recording bee behaviour outside the hive. a Flower visits by bees can be recorded using motion sensitive cameras on artificial flowers. The flight path of a bumblebee equipped with $\mathbf{b}$ a harmonic transponder can be recorded with a $\mathbf{c}$ harmonic radar. Picture credits: a Mathieu Lihoreau, b and $\mathbf{c}$ Joe Woodgate

with sensors, have flourished for improving precision beekeeping (e.g. Bromenshenk et al. 2005). Here we argue that these fast-developing automated colony monitoring systems constitute a powerful yet still under-exploited tool for fundamental research, which can provide new insight for interpreting a wide range of experimental data in different areas of bee biology, not just behaviour and ecology. As we have seen above, sensors can be combined to link individual behaviour inside and outside the hive, with colony performance and environmental conditions (Figure 3). Of course, many important parameters (e.g. parasite loads, pollutants, predation pressure) cannot yet be easily measured with automated devices (Box $1)$, but it is possible to evaluate them with conventional approaches to complement connectedhives data. Below, we discuss how future developments of connected hive systems will help explore new grounds in several areas of bee research.

\section{Box 1. Some missing sensors}

New sensors are needed to study the multi-factorial impact of environmental stressors on bee colony health.

1. Predator counter. Invasive predators such as Asian hornets (Vespa velutina) are thought to significantly impact populations of domestic honey bees in Europe and Eastern Asia, but quantitative data are lacking (Monceau et al. 2014). Correlating hornet predation pressure with metrics of bee colony health will bring important answers for the development of population control strategies.
2. Sensor of nutritional quality of pollen and nectars entering the hive. Bees fed synthetic foods in the lab or outside flight cages balance their intake of proteins, carbohydrates, lipids and water at a colony level (Wright et al. 2018). How nutritional balance is achieved in nature, where foods are more diverse and temporarily available, and how this impact colony fitness is still an open question.

3. Pesticides and pollutants sensors. Many products, such as heavy metals, accumulate in the comb. These in hive contaminations may have dramatic effects on bee behaviour and colony growth (Calatayud-Vernich et al. 2019; Crall et al. 2018b; Hladun et al. 2016; Søvik et al. 2015), that remain to be quantified. Various micro sensors for air pollutants already exist and could be adapted to connected hive systems(Choi et al. 2009).

4. Electromagnetic fields sensors. Bees use natural electric fields to forage (Clarke et al. 2013) but artificial (low frequency) fields impair their cognition (Shepherd et al. 2018). Correlating exposure to electromagnetic fields with colony dynamics will inform about the impact of electromagnetic pollution (Wi-Fi, power lines, phones), including communication systems used for connected hives (Rehman et al. 2014), on bee health and pollination.

5. Parasites and pathogens counter. Automated estimation of bee parasite loads, for instance through continuous analyses of the faeces (for gut parasites) or screens at the bottom board of hives (for ectoparasites or fungi) would help understand the impact of these biological agents on bee behaviour and colony health.

6. Cognitive health sensor. Fine-tuned cognition required for foraging on flowers, is a major point of vulnerability for bees facing environmental stressors (Klein et al. 2017). Correlating environmental quality (exposure to stressors) with cognitive scores (by testing large numbers of bees for a variety of specific cognitive tasks using automated setups) will help identify the effects of specific stressors and their combinations on bee cognition. 


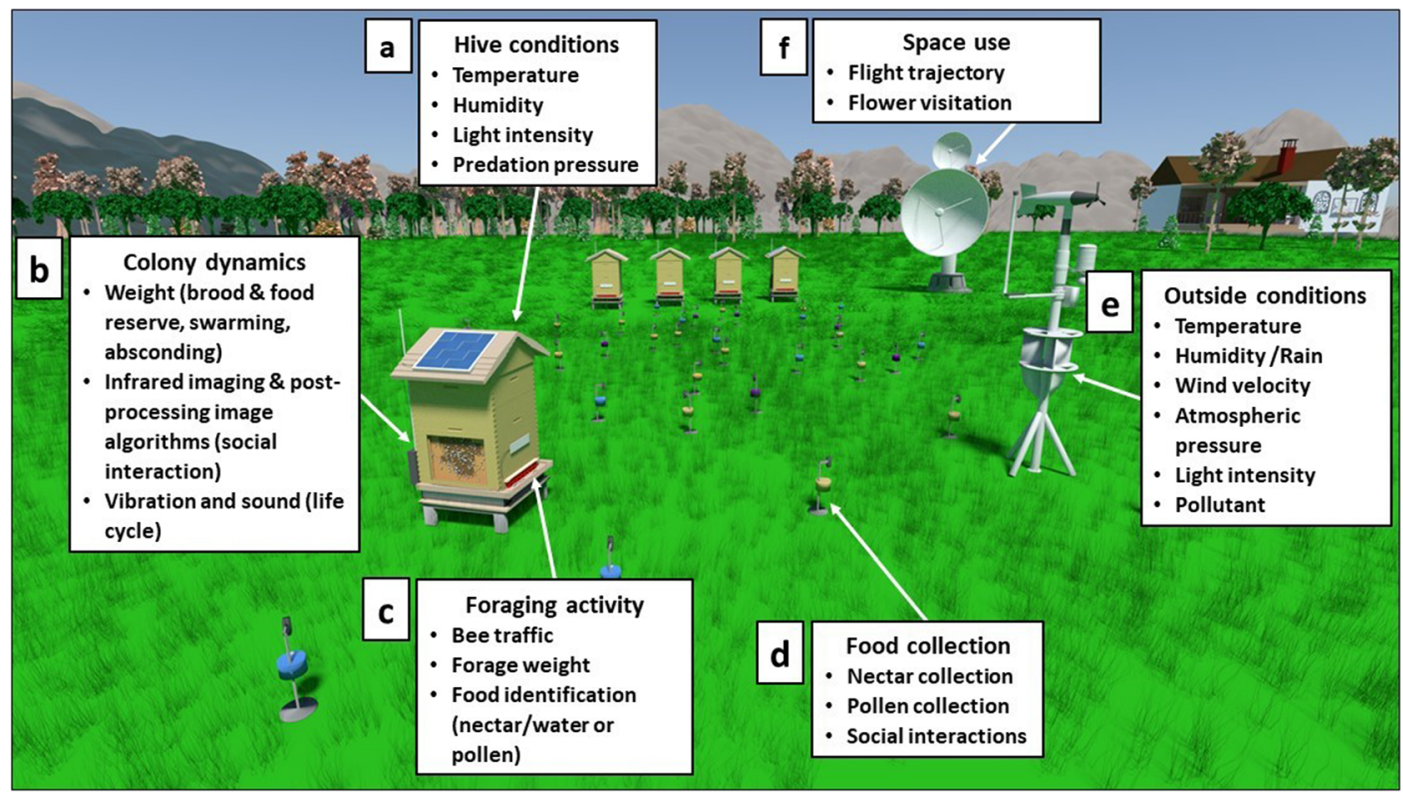

Figure 3. Connecting bees, hives and the foraging environment. Hypothetical scheme of a network of connected devices to record bee behaviour inside and outside the hive. Connected glass hive in a field equipped with sensors to collect data about (a) in-hive conditions, (b) colony dynamics and (c) bee foraging activity. (d) Feeding events are recorded by sensors on artificial flowers. (e) Outside conditions are recorded by a weather station. (f) Flight trajectories of individual bees and flower visitations are recorded using a harmonic radar

Behavioural research will benefit from the combination of new automated quantitative approaches to discover and record new behaviours. For instance, while most studies on bee spatial behaviour have focused on how honey bee foragers find one or two food locations and recruit nestmates to these locations (Collett et al. 2013; von Frisch 1967), in nature bees are expected to visit hundreds of flowers per foraging trips, which may require exploiting large numbers of feeding sites simultaneously. How small brained bees efficiently navigate between multiple known locations is a major question in neuroethology with far reaching implications for pollination (Pasquaretta et al. 2017). Studies have begun to monitor the lifelong history of individual bees using harmonic radars (Woodgate et al. 2016). So far, however, this technology is limited to tracking one identified bee at a time. Other approaches such as weather radars (Loper et al. 1987) and light detection and ranging (LIDARs) (Carlsten et al. 2011) have been used to map the spatial density of bees at local scales but do not provide individual data. Bee counters yield data on the foraging activity of all bees at the hive entrance (Klein et al. 2019; Tenczar et al. 2014), but without information about the behaviour of bees outside the hive. Combining these technologies to track the behaviours of multiple individuals simultaneously inside and outside the nest has the potential to bring entirely new information about how bees use resources in space, whether they spatially or temporarily segregate, and how these collective behaviours are linked to colony performance. Ultimately, mapping bee foraging patterns on satellite data (e.g. to discriminate land cover (Gómez et al. 2016), agricultural practices (Bégué et al. 2018)) will yield critical information about which ecological parameters bees use to exploit their large-scale foraging environments.

Connected devices can also yield important insights into social evolution, for instance to clarify the question of interindividual behavioural variability in social insect colonies (Jandt et al. 
2014). Bees are known to express behavioural variability based on morphological and physiological differences associated with division of labour. Yet, growing evidences also indicate that individuals from the same caste show strong interindividual behavioural differences, for instance in foraging activity (Tenczar et al. 2014), foraging performance (Klein et al. 2017), speed and accuracy of decision-making (Chittka et al. 2003), and learning and memory (Cabirol et al. 2018). Behavioural differences have also been observed between colonies (Raine and Chittka 2008). Quantification of individual behaviour over long periods of time and across many hives located in different environments, as now possible with connected hives, can be powerful to inform about the mechanisms underpinning such diversity and help identify whether variability is a key adaptation or an emergent social phenomenon.

Automated quantitative approaches can also potentially greatly contribute to advance comparative research on pollinators. While studies using standalone connected hives or specific sensors have primarily focused on honey bees (Wario et al. 2017), and to a lesser extent on bumblebees (Crall et al. 2018a), this methodology is relevant to all central place foraging bees, including other social bees (such as stingless bees) but also solitary bees, that live in a nest in which sensors could be introduced (e.g. cameras, RFIDs). Recent studies emphasise the crucial ecological role of wild bees, whose majority is solitary (Michener 2000), and point out the need for more research on their fundamental biology to better understand the importance of biodiversity for pollination services (Garibaldi et al. 2016).

Another potential major contribution of connected hives is to conservation biology (Box 1). Bee populations are declining in most of the industrialised world (Potts et al. 2010). The main factors of stress have been identified, but the mechanisms triggering colony losses remain unclear (Goulson et al. 2015). This is because many environmental stressors do not kill the bees but have synergistic sublethal effects that impair the behaviour and cognition of individuals (Klein et al. 2017). Accurate characterisation of the environment surrounding hives and the long-term exposure of colonies to different stressors, together with extensive behavioural measures on bees, will offer the possibility to correlate the levels of exposures, the types of stressors and their combinations, which affect populations. Citizen science initiatives interconnecting academic research, private companies and public communities based on the utilisation of connected hives are blooming (e.g. http://worldbeeproject.org/). Ultimately, these approaches will allow researchers to access large amount of data in order to parameterise models of population growth (Becher et al. 2014; Khoury et al. 2011; Thorbek et al. 2017) and identify constructive interventions for improving conservation plans.

As the costs for electronics decrease and the precision and capacity of sensors increases, connected hives will likely become common tools for bee researchers in the near future. Just like glass hives led to major discoveries about in-hive bee biology, a broader usage of connected hives holds considerable promises for addressing new questions about bee behaviour and ecology while increasing the sample sizes, the statistical power of the analyses, and offering the possibility to take into account potential confounding factors such as hive history and environmental conditions in data interpretations. Automated approaches for behavioural quantification (reviewed in Meikle and Holst 2015) and analyses (i.e. behavioural mapping and unsupervised annotation (Brown and de Bivort 2018)) provide a solid toolkit for the development of computational apidology.

\section{ACKNOWLEDGEMENTS}

This article emerged from discussions with our colleagues of the APICampus/neOCampus consortium of the Federal University of Toulouse (Vincent Boitier, Nicolas Delcey, Véronique Gaildrat, Marie-Pierre Gleize, Rahim Kacimi, Christian Lubat, Eric Marchadier, Cagil Oksuztepe, Nicolas Rivière, François Thiébolt, Philippe Truillet, Nathalie del Vecchio). We thank two anonymous reviewers for useful comments on an earlier version of the manuscript.

Contributions $\mathrm{PM}, \mathrm{AB}$ and $\mathrm{ML}$ designed the review. $\mathrm{PM}, \mathrm{AB}, \mathrm{SK}, \mathrm{SK}, \mathrm{TMG}$ and $\mathrm{ML}$ wrote the article. 


\section{FUNDING INFORMATION}

The work was funded by the Federal University of Toulouse, the CNRS, a PhD fellowship from the Ministère de l'Enseignement Supérieur et de la Recherche to PM and S Klein, a PhD fellowship from Human Frontiers to $\mathrm{AB}$, a $\mathrm{PhD}$ fellowship from CIFRE/Koppert to $\mathrm{S}$ Kraus, a postdoctoral fellowship from the Fyssen Fondation to TGM, and a research grant from the Agence Nationale de la Recherche to ML (ANR-16-CE02-0002-01).

Surveillance automatisée du comportement des abeilles à l'aide de ruches connectées : Vers une apidologie computationnelle

ruche connectée / abeille mellifère / bourdon / surveillance automatisée / éthologie quantitative / capteurs

Automatisches Monitoring von Bienenverhalten durch verbundene Bienenkästen: Hin zu einer computergestützten Bienenhaltung

Verbundene Bienenkästen / Honigbienen / Hummeln / automatisches Monitoring / quantitative Ethologie / Sensoren

\section{REFERENCES}

Alaux, C., Crauser, D., Pioz, M., Saulnier, C., and Le Conte, Y. (2014). Parasitic and immune modulation of flight activity in honey bees tracked with optical counters. J. Exp. Biol. 217, 3416-3424. doi:https://doi. org/10.1242/jeb.105783.

Ayton, S., Tomlinson, S., Phillips, R. D., Dixon, K. W., and Withers, P. C. (2016). Phenophysiological variation of a bee that regulates hive humidity, but not hive temperature. J. Exp. Biol. 219, 1552-1562. doi:https://doi. org/10.1242/jeb.137588.

Bai, Y., and Ku, Y. (2008). Automatic room light intensity detection and control using a microprocessor and light sensors. IEEE Trans. Consum. Electron. 54, 11731176. doi:https://doi.org/10.1109/TCE.2008.4637603.

Basile, R., Pirk, C. W. W., and Tautz, J. (2008). Trophallactic activities in the honeybee brood nest Heaters get supplied with high performance fuel. Zoology 111, 433-441. doi:https://doi.org/10.1016/j. zool.2007.11.002.

Becher, M. A., Grimm, V., Thorbek, P., Horn, J., Kennedy, P. J., and Osborne, J. L. (2014). BEEHAVE: A systems model of honeybee colony dynamics and foraging to explore multifactorial causes of colony failure. J. Appl.
Ecol. 51, 470-482. doi:https://doi.org/10.1111/13652664.12222 .

Bégué, A., Arvor, D., Bellon, B., Betbeder, J., de Abelleyra, D., Ferraz, R. P. D., et al. (2018). Remote sensing and cropping practices: A review. Remote Sens. 10, 1-32. doi:https://doi.org/10.3390/rs10010099.

Bencsik, M., Le Conte, Y., Reyes, M., Pioz, M., Whittaker, D., Crauser, D., et al. (2015). Honeybee colony vibrational measurements to highlight the brood cycle. PLoS One 10, 1-16. doi:https://doi.org/10.1371/journal.pone.0141926.

Bordier, C., Klein, S., Le Conte, Y., Barron, A. B., and Alaux, C. (2018). Stress decreases pollen foraging performance in honeybees. J. Exp. Biol. 221, jeb171470. doi:https://doi.org/10.1242/jeb.171470.

Branson, K., Robie, A. A., Bender, J., Perona, P., and Dickinson, M. H. (2009). High-throughput ethomics in large groups of Drosophila. Nat. Methods 6, 451457. doi:https://doi.org/10.1038/nmeth.1328.

Breeze, T. D., Vaissière, B. E., Bommarco, R., Petanidou, T., Seraphides, N., Kozák, L., et al. (2014). Agricultural policies exacerbate honeybee pollination service supplydemand mismatches across europe. PLoS One 9, e82996. doi:https://doi.org/10.1371/journal.pone.0082996.

Bromenshenk, J. J., Smith, G. C., King, B. E., Seccomb, R. A., and Alnasser, G. (1996). New and improved methods for monitoring air quality and the terrestrial environment. University of Montana Available at: https://apps.dtic.mil/dtic/tr/fulltext/u2/a326262.pdf.

Bromenshenk, J., Seccomb, R. A., Rice, S. D., and Etter, R. T. (2005). Honey bee monitoring system for monitoring bee colonies in a hive. US Patents, 6,910,941 B2.

Bromenshenk, J., Henderson, C., Seccomb, R., Welch, P., Debnam, S., and Firth, D. (2015). Bees as biosensors: Chemosensory ability, honey bee monitoring systems, and emergent sensor technologies derived from the pollinator syndrome. Biosensors 5, 678-711. doi:https://doi.org/10.3390/bios5040678.

Brown, A. E. X., and de Bivort, B. (2018). Ethology as a physical science. Nat. Phys. 14, 653-657. doi:https://doi.org/10.1038/s41567-018-0093-0.

Buatois, A., and Lihoreau, M. (2016). Evidence of trapline foraging in honeybees. J. Exp. Biol. 219, 2426-2429. doi:https://doi.org/10.1242/jeb.143214.

Cabirol, A., Cope, A. J., Barron, A. B., and Devaud, J.-M. (2018). Relationship between brain plasticity, learning and foraging performance in honey bees. PLoS One 13, e0196749. doi:https://doi.org/10.1371/journal. pone.0196749.

Calatayud-Vernich, P., Calatayud, F., Simó, E., Pascual Aguilar, J. A., and Picó, Y. (2019). A two-year monitoring of pesticide hazard in-hive: High honey bee mortality rates during insecticide poisoning episodes in apiaries located near agricultural settings. Chemosphere 232, 471-480. doi:https://doi. org/10.1016/j.chemosphere.2019.05.170.

Carlsten, E. S., Wicks, G. R., Repasky, K. S., Carlsten, J. L., Bromenshenk, J. J., and Henderson, C. B. (2011). Field demonstration of a scanning lidar and detection 
algorithm for spatially mapping honeybees for biological detection of land mines. Appl. Opt. 50, 2112. doi:https://doi.org/10.1364/AO.50.002112.

Cejrowski, T., Szymański, J., Mora, H., and Gil, D. (2018). "Detection of the bee queen presence using sound analysis," in Intelligent information and database systems , 297-306. doi:https://doi.org/10.1007/978-3319-75420-8 28.

Chittka, L., Dyer, A. G., Bock, F., and Dornhaus, A. (2003). Bees trade off foraging speed for accuracy. Nature 424, 388. doi:https://doi.org/10.1038/424388a.

Choi, S., Kim, N., Cha, H., and Ha, R. (2009). Micro sensor node for air pollutant monitoring: hardware and software issues. Sensors 9, 7970-7987. doi:https://doi. org/10.3390/s91007970.

Clarke, D., and Robert, D. (2018). Predictive modelling of honey bee foraging activity using local weather conditions. Apidologie 49, 386-396. doi:https://doi. org/10.1007/s13592-018-0565-3.

Clarke, D., Whitney, H., Sutton, G., and Robert, D. (2013). Detection and learning of floral electric fields by bumblebees. Science (80). 340, 66-69. doi:https://doi. org/10.1126/science. 1230883 .

Collett, M., Chittka, L., and Collett, T. S. (2013). Spatial memory in insect navigation. Curr. Biol. 23, 789-800. doi:https://doi.org/10.1016/j.cub.2013.07.020.

Crall, J. D., Gravish, N., Mountcastle, A. M., Kocher, S. D., Oppenheimer, R. L., Pierce, N. E., et al. (2018a). Spatial fidelity of workers predicts collective response to disturbance in a social insect. Nat. Commun. 9, 113. doi:https://doi.org/10.1038/s41467-018-03561-w.

Crall, J. D., Switzer, C. M., Oppenheimer, R. L., Ford Versypt, A. N., Dey, B., Brown, A., et al. (2018b). Neonicotinoid exposure disrupts bumblebee nest behavior, social networks, and thermoregulation. Science 362, 683-686. doi:https://doi.org/10.1126/science. aat1598.

Darwin, C. (1859). On the origin of species by means of natural selection or the preservation of favoured races in the struggle for life. London : John Murray doi:https://doi.org/10.5962/bhl.title.59991.

de Souza, P., Marendy, P., Barbosa, K., Budi, S., Hirsch, P., Nikolic, N., et al. (2018). Low-cost electronic tagging system for bee monitoring. Sensors 18, 2124. doi:https://doi.org/10.3390/s18072124.

Debauche, O., Moulat, M. El, Mahmoudi, S., Boukraa, S., Manneback, P., and Lebeau, F. (2018). Web monitoring of bee health for researchers and beekeepers based on the Internet of Things. Procedia Comput. Sci. 130, 991998. doi:https://doi.org/10.1016/j.procs.2018.04.103.

Edwards Murphy, F., Magno, M., O’Leary, L., Troy, K., Whelan, P., and Popovici, E. M. (2015). Big brother for bees (3B) Energy neutral platform for remote monitoring of beehive imagery and sound. in 6th International Workshop on Advances in Sensors and Interfaces (IWASI) (IEEE), 106-111. doi:https://doi.org/10.1109 /IWASI.2015.7184943.

Egnor, S. E. R., and Branson, K. (2016). Computational analysis of behavior. Annu. Rev. Neurosci. 39, 217-
236. doi:https://doi.org/10.1146/annurev-neuro070815-013845.

Flores, J. M., Gil-Lebrero, S., Gámiz, V., Rodríguez, M. I., Ortiz, M. A., and Quiles, F. J. (2019). Effect of the climate change on honey bee colonies in a temperate Mediterranean zone assessed through remote hive weight monitoring system in conjunction with exhaustive colonies assessment. Sci. Total Environ. 653, 1111-1119. doi:https://doi.org/10.1016/j.scitotenv.2018.11.004.

Garibaldi, L. A., Carvalheiro, L. G., Vaissière, B. E., Gemmill-Herren, B., Hipólito, J., Freitas, B. M., et al. (2016). Mutually beneficial pollinator diversity and crop yield outcomes in small and large farms. Science 351, 388-391. doi:https://doi.org/10.1126/science. aac 7287.

Gernat, T., Rao, V. D., Middendorf, M., Dankowicz, H., Goldenfeld, N., and Robinson, G. E. (2018). Automated monitoring of behavior reveals bursty interaction patterns and rapid spreading dynamics in honeybee social networks. Proc. Natl. Acad. Sci. USA 115, 1433-1438. doi:https://doi.org/10.1073 /pnas. 1713568115 .

Gill, R. J., Ramos-Rodriguez, O., and Raine, N. E. (2012). Combined pesticide exposure severely affects individual- and colony-level traits in bees. Nature 491, 105-108. doi:https://doi.org/10.1038 /nature11585.

Gómez, C., White, J. C., and Wulder, M. A. (2016). Optical remotely sensed time series data for land cover classification: A review. ISPRS J. Photogramm. Remote Sens. 116, 55-72. doi:https://doi.org/10.1016/j. isprsjprs.2016.03.008.

Goulson, D. (2010). Bumblebees: Behaviour, Ecology, and Conservation. Oxford University Press.

Goulson, D., Nicholls, E., Botías, C., and Rotheray, E. L. (2015). Bee declines driven by combined stress from parasites, pesticides, and lack of flowers. Science 347 , 1255957 . doi:https://doi.org/10.1126 /science.1255957.

Henry, M., Béguin, M., Requier, F., Rollin, O., Odoux, J. F., Aupinel, P., et al. (2012). A common pesticide decreases foraging success and survival in honey bees. Science 336, 348-350. doi:https://doi.org/10.1126 /science.1215039.

Higes, M., Martín-Hernández, R., Botías, C., Bailón, E. G., González-Porto, A. V., Barrios, L., et al. (2008). How natural infection by Nosema ceranae causes honeybee colony collapse. Environ. Microbiol. 10, 2659-2669. doi:https://doi.org/10.1111/j.1462-2920.2008.01687.x.

Hladun, K. R., Di, N., Liu, T.-X., and Trumble, J. T. (2016). Metal contaminant accumulation in the hive: Consequences for whole-colony health and brood production in the honey bee (Apis mellifera L.). Environ. Toxicol. Chem. 35, 322-329. doi:https://doi.org/10.1002 /etc.3273.

Holst, N., and Meikle, W. G. (2018). Breakfast canyon discovered in honeybee hive weight curves. Insects 9. doi:https://doi.org/10.3390/insects9040176.

Human, H., Nicolson, S. W., and Dietemann, V. (2006). Do honeybees, Apis mellifera scutellata, regulate 
humidity in their nest? Naturwissenschaften 93, 397401. doi:https://doi.org/10.1007/s00114-006-0117-y.

Jandt, J. M., Bengston, S., Pinter-Wollman, N., Pruitt, J. N., Raine, N. E., Dornhaus, A., et al. (2014). Behavioural syndromes and social insects: Personality at multiple levels. Biol. Rev. 89, 48-67. doi:https://doi. org/10.1111/brv.12042.

Khoury, D. S., Myerscough, M. R., and Barron, A. B. (2011). A quantitative model of honey bee colony population dynamics. PLoS One 6, 2-7. doi:https://doi.org/10.1371/journal. pone.0018491.

Klein, B. A., Stiegler, M., Klein, A., and Tautz, J. (2014). Mapping sleeping bees within their nest: spatial and temporal analysis of worker honey bee sleep. PLoS One 9, e102316. doi:https://doi.org/10.1371/journal. pone. 0102316.

Klein, S., Cabirol, A., Devaud, J. M., Barron, A. B., and Lihoreau, M. (2017). Why bees are so vulnerable to environmental stressors. Trends Ecol. Evol. 32, 268278. doi:https://doi.org/10.1016/j.tree.2016.12.009.

Klein, S., Pasquaretta, C., He, X. J., Perry, C., Søvik, E., Devaud, J.-M., et al. (2019). Honey bees increase their foraging performance and frequency of pollen trips through experience. Sci. Rep. 9, 6778. doi:https://doi. org/10.1038/s41598-019-42677-x.

Lach, L., Kratz, M., and Baer, B. (2015). Parasitized honey bees are less likely to forage and carry less pollen. J. Invertebr. Pathol. 130, 64-71. doi:https://doi. org/10.1016/j.jip.2015.06.003.

Lettmann, M., and Chauzat, M.-P. (2018). Les outils connectés en apiculture: Evaluation de leurs application auprès des apiculteurs français. https://be.anses. $\mathrm{fr} / \mathrm{sites} / \mathrm{default} / \mathrm{files} / \mathrm{O}-028$ 2018-12-28_Outilsabeilles_Lettmann_VF.pdf

Lihoreau, M., Raine, N. E., Reynolds, A. M., Stelzer, R. J., Lim, K. S., Smith, A. D., et al. (2012). Radar tracking and motion-sensitive cameras on flowers reveal the development of pollinator multi-destination routes over large spatial scales. PLoS Biol. 10, 19-21. doi:https://doi.org/10.1371/journal.pbio.1001392.

Lihoreau, M., Chittka, L., and Raine, N. E. (2016). Monitoring flower visitation networks and interactions between pairs of bumble bees in a large outdoor flight cage. PLoS One 11, e0150844. doi:https://doi. org/10.1371/journal.pone.0150844.

Loper, G. M., Wolf, W. W., and Taylor Jr., O. R. (1987). Detection and monitoring of honey bee drone congregation areas by radar. Apidologie 18, 163-172. doi:https://doi.org/10.1051/apido:19870206.

Meikle, W. G., and Holst, N. (2015). Application of continuous monitoring of honeybee colonies. Apidologie 46, 10-22. doi:https://doi.org/10.1007/s13592-0140298-X.

Meikle, W. G., Rector, Brian, G., Mercadier, G., and Holst, N. (2008). Within-day variation in continuous hive weight data as a measure of honey bee colony activity. Apidologie 39, 694-707. doi:https://doi.org/10.1051/apido:2008055.

Meikle, W. G., Holst, N., Colin, T., Weiss, M., Carroll, M. J., McFrederick, Q. S., et al. (2018). Using within-day hive weight changes to measure environmental effects on honey bee colonies. PLoS One 13, 1-21. doi:https://doi.org/10.1371/journal.pone.0197589.

Mendelsohn, R., Kurukulasuriya, P., Basist, A., Kogan, F., and Williams, C. (2007). Climate analysis with satellite versus weather station data. Clim. Change 81, 71-83. doi:https://doi.org/10.1007/s10584-006-9139-x.

Michener, C. D. (2000). The bees of the world. JHU press.

Monceau, K., Bonnard, O., and Thiéry, D. (2014). Vespa velutina: A new invasive predator of honeybees in Europe. J. Pest Sci. (2004). 87, 1-16. doi:https://doi. org/10.1007/s10340-013-0537-3.

Ngo, T. N., Wu, K. C., Yang, E. C., and Lin, T. Te (2019). A real-time imaging system for multiple honey bee tracking and activity monitoring. Comput. Electron. Agric. 163, 104841. doi:https://doi.org/10.1016/j. compag.2019.05.050.

Nieh, J. C. (2010). A negative feedback signal that is triggered by peril curbs honey bee recruitment. Curr. Biol. 20, 310-315. doi:https://doi.org/10.1016/j. cub.2009.12.060.

Ohashi, K., Thomson, J. D., and D'Souza, D. (2007). Trapline foraging by bumble bees: IV. Optimization of route geometry in the absence of competition. Behav. Ecol. 18, 1-11. doi:https://doi.org/10.1093 /beheco/arl053.

Ohashi, K., Leslie, A., and Thomson, J. D. (2008). Trapline foraging by bumble bees: V. Effects of experience and priority on competitive performance. Behav. Ecol. 19, 936-948. doi:https://doi.org/10.1093/beheco/arn048.

Ohashi, M., Okada, R., Kimura, T., and Ikeno, H. (2009). Observation system for the control of the hive environment by the honeybee (Apis mellifera). Behav. Res. Methods 41, 782-786. doi:https://doi.org/10.3758 /BRM.41.3.782.

Pasquaretta, C., Jeanson, R., Andalo, C., Chittka, L., and Lihoreau, M. (2017). Analysing plant-pollinator interactions with spatial movement networks. Ecol. Entomol. 42, 4-17. doi:https://doi.org/10.1111/een.12446.

Pasquaretta, C., Jeanson, R., Pansanel, J., Raine, N. E., Chittka, L., and Lihoreau, M. (2019). A spatial network analysis of resource partitioning between bumblebees foraging on artificial flowers in a flight cage. Mov. Ecol. 7, 4. doi:https://doi.org/10.1186/s40462019-0150-z.

Potts, S. G., Biesmeijer, J. C., Kremen, C., Neumann, P., Schweiger, O., and Kunin, W. E. (2010). Global pollinator declines: trends, impacts and drivers. Trends Ecol. Evol. 25, 345-353. doi:https://doi.org/10.1016 j.tree.2010.01.007.

Raine, N. E., and Chittka, L. (2008). The correlation of learning speed and natural foraging success in bumblebees. Proc. R. Soc. B Biol. Sci. 275, 803-808. doi:https://doi.org/10.1098/rspb.2007.1652.

Rangel, J., and Seeley, T. D. (2008). The signals initiating the mass exodus of a honeybee swarm from its nest. Anim. Behav. 76, 1943-1952. doi:https://doi. org/10.1016/j.anbehav.2008.09.004. 
Aqeel-ur Rehman, Abbasi, A. Z., Islam, N., and Shaikh, Z. A. (2014). A review of wireless sensors and networks' applications in agriculture. Comput. Stand. Interfaces 36, 263-270. doi:https://doi.org/10.1016/j.csi.2011.03.004.

Russell, A. L., Morrison, S. J., Moschonas, E. H., and Papaj, D. R. (2017). Patterns of pollen and nectar foraging specialization by bumblebees over multiple timescales using RFID. Sci. Rep. 7, 42448. https://doi. org/10.1038/srep42448.

Seeley, T. D. (1974). Atmospheric carbon dioxide regulation in honey-bee (Apis mellifera) colonies. J. Insect Physiol. 20, 2301-2305. doi:https://doi.org/10.1016 /0022-1910(74)90052-3.

Seeley, T. D. (2010). Honeybee democracy. Princeton University Press.

Seeley, T. D. (2014). Honeybee ecology: A study of adaptation in social life. Princeton University Press.

Shaw, J. A., Nugent, P. W., Johnson, J., Bromenshenk, J. J., Henderson, C. B., and Debnam, S. (2011). Long-wave infrared imaging for non-invasive beehive population assessment. Opt. Express 19, 399. doi:https://doi. org/10.1364/OE.19.000399.

Shepherd, S., Lima, M. A. P., Oliveira, E. E., Sharkh, S. M., Jackson, C. W., and Newland, P. L. (2018). Extremely low frequency electromagnetic fields impair the cognitive and motor abilities of honey bees. Sci. Rep. , 1-9. doi:https://doi.org/10.1038/s41598-018-26185-y.

Simpson, J. (1961). Nest climate regulation in honey bee colonies. Science 133, 1327-1333.

Søvik, E., Perry, C. J., LaMora, A., Barron, A. B., and BenShahar, Y. (2015). Negative impact of manganese on honeybee foraging. Biol. Lett. 11, 1-4. doi:https://doi. org/10.1098/rsbl.2014.0989.

Stalidzans, E., Zacepins, A., Kviesis, A., Brusbardis, V., Meitalovs, J., Paura, L., et al. (2017). Dynamics of weight change and temperature of Apis mellifera (hymenoptera: Apidae) colonies in a wintering building with controlled temperature. J. Econ. Entomol. 110, 111. doi:https://doi.org/10.1093/jee/tow282.

Stelzer, R. J., Stanewsky, R., and Chittka, L. (2010). Circadian foraging rhythms of bumblebees monitored by radio-frequency identification. J. Biol. Rhythms 25, 257-267. doi:https://doi.org/10.1177 /0748730410371750.

Streit, S., Bock, F., Pirk, C. W. W., and Tautz, J. (2003). Automatic life-long monitoring of individual insect behaviour now possible. Zoology 106, 169-171. doi:https://doi.org/10.1078/0944-2006-00113.

Struye H. M., Mortier J. H., Arnold, G., Miniggio, C., and Borneck, R. (1994). Microprocessor-controlled monitoring of honeybee flight activity at the hive entrance. Apidologie 25, 384-395. doi:https://doi.org/10.1051 /apido:19940405.

Tenczar, P., Lutz, C. C., Rao, V. D., Goldenfeld, N., and Robinson, G. E. (2014). Automated monitoring reveals extreme interindividual variation and plasticity in honeybee foraging activity levels. Anim. Behav. 95, 4148. doi:https://doi.org/10.1016/j.anbehav.2014.06.006.
THE RESPONSE OF HONEY BEES TO VARIATIONS IN SOLAR RADIATION AND TEMPERATURE Apidologie 12 (1981) 319-328 DOI:https://doi. org/10.1051/apido:19810402.

Thorbek, P., Campbell, P. J., and Thompson, H. M. (2017). Colony impact of pesticide-induced sublethal effects on honeybee workers: A simulation study using BEEHAVE. Environ. Toxicol. Chem. 36, 831-840. doi:https://doi.org/10.1002/etc.3581.

Transmission of vibration across honeycombs and its detection by bee leg receptors D Sandeman, J Tautz, M Lindauer Journal of Experimental Biology 1996 199: 2585-2594;

Tsvetkov, N., Samson-Robert, O., Sood, K., Patel, H. S., Malena, D. A., Gajiwala, P. H., et al. (2017). Chronic exposure to neonicotinoids reduces honey bee health near corn crops. Science 356, 1395-1397. doi:https://doi.org/10.1126/science.aam7470.

Vidrascu, M. G., Svasta, P. M., and Vladescu, M. (2016). High reliability wireless sensor node for bee hive monitoring. IEEE 22nd Int. Symp. Des. Technol. Electron. Packag. SIITME 2016, 134-138. doi:https://doi. org/10.1109/SIITME.2016.7777262.

von Frisch, K. (1967). The Dance Language and Orientation of Bees. Harvard University Press.

Wario, F., Wild, B., Rojas, R., and Landgraf, T. (2017). Automatic detection and decoding of honey bee waggle dances. PLoS One 12, 1-16. doi:https://doi. org/10.1371/journal.pone.0188626.

Wild, B., Sixt, L., and Landgraf, T. (2018). Automatic localization and decoding of honeybee markers using deep convolutional neural networks. arXiv.org, 1-20.

Woodgate, J. L., Makinson, J. C., Lim, K. S., Reynolds, A. M., and Chittka, L. (2016). Life-long radar tracking of bumblebees. PLoS One 11, 1-22. doi:https://doi. org/10.1371/journal.pone.0160333.

Woodgate, J. L., Makinson, J. C., Lim, K. S., Reynolds, A. M., and Chittka, L. (2017). Continuous radar tracking illustrates the development of multi-destination routes of bumblebees. Sci. Rep. 7, 17323. doi:https://doi. org/10.1038/s41598-017-17553-1.

Woods, E. F. (1957). Means for detecting and indicating the activities of bees and conditions in beehives. US Patents, 2,806,082.

Wright, G. A., Nicolson, S. W., and Shafir, S. (2018). Nutritional physiology and ecology of honey bees. Annu. Rev. Entomol. 63, 327-344. doi:https://oi. org/10.1146/annurev-ento-020117-043423.

Zhu, X., Wen, X., Zhou, S., Xu, X., Zhou, L., and Zhou, B. (2019). The temperature increase at one position in the colony can predict honey bee swarming (Apis cerana). J. Apic. Res. 58, 489-491. doi:https://doi.org/10.1080 /00218839.2019.1632149.

Publisher's note Springer Nature remains neutral with regard to jurisdictional claims in published maps and institutional affiliations. 